\title{
Bite Injuries to the Hand: Microbiology, Virology and Management
}

\author{
M. Malahias ${ }^{1}$, D. Jordan ${ }^{2}$, O. Hughes ${ }^{2}$, Wasim S. Khan ${ }^{3}$, S. Hindocha ${ }^{*}, 2$ \\ ${ }^{I}$ Plastic Surgery Department, Good Hope Hospital, West Midlands, B75 7RR, UK \\ ${ }^{2}$ Plastic Surgery Department, Whiston Hospital, Liverpool, L35 5DR, UK \\ ${ }^{3}$ University College London Institute of Orthopaedics \& Musculoskeletal Sciences, Royal National Orthopaedic \\ Hospital, Stanmore, London, HA7 4LP, UK
}

\begin{abstract}
Bites to the human hand, be it from a pet, a stray animal or even a fellow human, may often have dire consequences for the person suffering the insult. Bites by mammals are a common problem and they account for up to $1 \%$ of all visits to hospital emergency rooms, in the UK. Clenched fist injuries to the mouth ('fight bite') are notorious for being the worst human bites. Bite injuries of the hand and their related infections must be monitored vigilantly and managed proactively, by experts in this field of surgery. In this review article we discuss the associated microbiology and virology of these injuries as well as their management.
\end{abstract}

Keywords: Animal bite, bite, fight-bite, hand, human bite, microbiology, virology.

\section{INTRODUCTION}

Bites to the human hand, be it from a pet, a stray animal or even a fellow human, may often have dire consequences for the person suffering the insult. Anatomically, the hand is a complex structure that enables us to perform fine, epicretic tasks. This sets us apart from the simian species that with a lack of opposition of the thumb have a much less sophisticated 'grasper' to interact with their surroundings.

The spectrum of complications stemming from a mismanaged infected bite to the hand ranges from cellulitis of the injured area to amputation of the affected part of the hand, with obvious socio-economic implications for victims and their dependants.

Hand trauma, is mainly found in the male sex, affecting the younger population and in the majority of cases is related to work, or assault injuries [1-3]. Data revealed in 2007 by The British Society for Surgery of the Hand [4] showed that $20 \%$ of patients attending the emergency room suffered from hand injuries, resulting in more than 1.36 million attendances for hand injuries in the United Kingdom each year. One in five of these injuries $(271,000)$ required specialist care, and 71,000 patients required surgical intervention $[5,6]$.

Almost $1 \%$ of all visits to hospital emergency rooms in the United Kingdom are due to animal bites, with dog and cat bites being the most common. People are usually bitten by their own pets or by an animal known to them, with school-age children amounting to nearly $50 \%$ of those bitten [7]. It is worth noting that cat bites are more likely to lead to infection of the bitten hand when compared to dog bites [8]. In the USA, approximately 1 to 2 million Americans suffer

*Address correspondence to this author at the Sandip Hindocha, Plastic Surgery Department, Whiston Hospital, Warrington Road, Liverpool, L35 5DR, UK; Tel: + 44(0)1244366265; Fax: +44(0)1244366265;

E-mail: hindocha2001@yahoo.com from cat and dog bites each year [9], it is estimated that half of the American population will be bitten by an animal or another human being during their lifetime [10]. Snake and Spider bites amount to a large number of hospital attendances in rural areas and more exotic parts of the world $[11,12]$.

Closed fist punches to the human mouth ('fight bites') are notorious for being associated with the worst bite-related infections [13]. They are often underestimated and treated as 'minor injuries' without the health practitioner realising that the extensor tendon, the joint capsule and/or the deeper connective tissues may have been inoculated with oral bacteria $[13,14]$. Due to the limited soft tissue envelope that covers the deeper structures and the numerous tight compartments, bite wounds to the hand have a higher infection rate, when compared to bites to other parts of the human body [15]. Unusual microbiological contamination often complicates human and animal bites, as these are often associated with plant, water and soil exposures [14]. Therefore, due to the great variety of bite wound sources and the complex polymicrobial organisms implicated, they deserve special attention [16-18]. Transmission of viruses are less common, especially after human bites, but hepatitis B and C, HIV, syphilis, HSV and HTLV-1 have been documented [19-25].

Delayed medical attention related to initial management of washout can result in varying degrees of cellulitis and local inflammation on presentation, which is more prolific in the immuno-compromised patient including diabetics and smokers [26, 27]. Morbidity related to bites is normally related to infectious complications. Antibiotics should be used as an adjunct to thorough washout as opposed to an alternative [7], but there is no set consensus on their use in these injuries. If the wound is not infected on presentation, wound cultures are not indicated as they do not predict infection or the responsible pathogen, but prophylactic 
antibiotics are considered normal practice where any suspicion of future infection is thought [28, 29]. Zubowicz [29] showed a $47 \%$ infection rate in patients treated with placebo versus $0 \%$ in antibiotic prophylaxis patients, although similar studies in lower risk patients (not breaching dermis or in extremities) have shown no greater benefit in antibiotic prophylaxis [30, 31]. For this reason injuries deeper than the epidermis, involving the extremities, joints or cartilaginous areas, as well as delayed presentation longer than nine hours require antibiotic prophylaxis $[32,33]$ and particularly in injuries involving a human bite [7, 34].

If there is any indication of infection, cultures should be taken and longer cultures may find slow growing pathogens. If the use of antibiotics is not thought necessary, review of the patient and wound at 48-72 hours should be mandatory in the author's opinion.

Any associated fracture underlying a penetrating wound automatically grades the injury as an open fracture and depending on the amount of soft tissue and vascular injury, its management will almost always warrant hospital admission and intravenous antibiotic therapy. These injuries need to be assessed by an appropriate ortho-plastic surgeon and treated as deemed appropriate.

\section{INFECTIONS IN BITE INJURIES}

Up to $20 \%$ of bite injuries reportedly become infected; the degree of infection varying based on the depth of injury, amount of soft tissue injury and source of injury, and can push this number nearer $50 \%$ in the immunocompromised [35-38]. Microbiologically, these injuries are often polymicrobial with a large number of both aerobic and anaerobic pathogens. The more common culprits include Staphylococcus aureus, Steptococci family, as well as Haemophilus, Eikenella corrodens and Bacteroides species. Numerous other anaerobic and aerobic pathogens have also been documented as being present $[17,18]$.

$30 \%$ of human bite related injuries grow isolated cultures of Staphylococcus aureus that, although is a normal skin flora, is also responsible for the most severe infections and related complications. Its presence is likely to be secondary to the injury, as opposed to the other bacteria discussed below [39-42]. Staphylococcal and Streptococcal combinations are often seen in fight-bite injuries. Eikenella corrodens is found in a similar number of injuries and is more associated with chronic abscesses. It is a gram-negative bacillary infection and often seen in human bite related injuries [7, 17] Other anaerobic species also include Bacteroides and Peptostreptococcus type cultures [17].

Cat and dog bites are particularly difficult to treat due to the incidence of involvement of Pasteurella multocida, a gram-negative rod, which has also been seen in cat scratch and even wound licked injuries; related infections often presents early [17, 43]. Pasteurella canis is another bacterium often seen more specifically related to dog bites [44]. Pasteurella multocida has been seen to cause pneumonia and widespread sepsis [45]. Often its treatment is delayed by the wrong choice of antibiotic therapy in the first instance and chronic infection can lead to osteomyelitis [46].
Cat scratch disease, includes cat scratches, bites and even flea bites, and deserves mentioning. It is caused by Bartonella henselae and affects both immunocompromised and normal hosts, although more commonly seen in children. It presents with the primary injury and a self-limited regional lymphadenopathy, and is associated with life threatening complication in up to $14 \%$ of positive cases. This protobacterium is difficult to isolate from tissue specimens but antibodies may be picked up from blood samples. Antibiotic therapy is not indicated unless life-threatening complications are present $[47,48]$.

A rarer anaerobic gram-negative rod, Capnocytophaga canimorsus, is present in cat and dog mouth flora and has been seen to cause bacteraemia and sepsis, as well as unexpected death, particularly in the immunocompromised (including asplenia), and should be considered if a fever is present [17, 49-51] Bites involving salt or fresh water species, and even contamination with these solutions, have been shown to grow Mycobacterium species, particularly Mycoplasma marinum [52, 53]. Streptobacillicus moniliformis causes rat bite fever, more commonly seen in Asia, but related to rodent bites including squirrels, ferrets and mice. It has been seen in cat and dog bites and is usually treated well with penicillin related antibiotics [54].

\section{MANAGEMENT OF BITE INJURIES}

The ABCDE mantra of emergency management needs to be remembered when dealing with a hand bite patient, as even small wounds may distract from associated serious injuries (e.g. head injuries) the victim may have incurred when trying to evade the initial hand trauma. The nature of wounds encountered varies greatly depending on the mechanism of injury and animal species involved. Cat bites, for example, are deeper puncture-type wounds, whereas human or dog bites may have an associated degree of crush injury. With fight bite injuries it is important to remember that they can result in a breach of the joint capsule that may result in purulent arthritis [55]. Occult fractures of the metacarpal head that are easily missed on plain radiographs are another important point that needs to be kept in mind [56].

Copious oral or intravenous analgesia, especially with large wounds or venomous bites that may be extremely painful, must be administered. When administering a regional nerve block with Lignocaine or longer acting Chirocaine, care must be taken to avoid causing injury to the nerve that is being targeted.

\section{Venomous Bites}

Management of snake bites are usually dependant on the snake in question and descriptions of the reptile should be taken from the patient and witnesses and related to the appropriate authority. After immediate resuscitation, if a venomous culprit is identified the appropriate anti-venom should be administered. In the United Kingdom most snake bites relate to non-venomous bites where no antibiotic therapy is indicated. Anti-anaphylaxis therapy related to the bite is often all that is required, unless surgery is indicated due to acute regional swelling and risk of compartment syndrome $[57,58]$. 
Other venomous bites, including marine life such as stonefish and other animals are reported and expert advice should be sought [59].

\section{Antibiotic Choice}

Current guidance shows penicillin based antibiotics such as Flucloxacillin are useful in soft tissue infections. Coamoxiclav is more suitable for its broad spectrum of bacterial therapy and is commonly used in the management of open fractures [60-62]. Likewise, the ineffectiveness of Flucloxacillin, Erythromycin and Cephalosporins in Pasteurella infections means that Co-amoxiclav should be used routinely in animal bites and scratches [62, 63] Clindamycin is a good alternative in penicillin-allergic patients, unless Pasteurella species is present in which case discussion with a microbiologist is required [64]. Alternatively Doxycycline and Metronidazole can be used [62].

Cephalosporins have been shown to be ineffective in Eikenella corrodens infections, and Eikenella species have been shown to be resistant to Clindamycin and Metronidazole. If its presence is found, discussion with a microbiology specialist should be undertaken [62]. Therapy should be continued for between 10 and 14 days for cellulites, and at least 3 weeks with any deeper tissue involvement.

\section{Virus Transmission}

Most virus transmission is through human-to-human bite, although it is feasible in animal bites. HIV transmission rate is unknown but is likely to be extremely small, whereas Hepatitis $\mathrm{C}$ is more easily transmitted through a bite. HIV has been identified in affected patients' saliva at lower levels than that found in the blood. It is however suggested that salivary inhibitors are very good at inhibiting its infectiousness [20-23, 65, 66]. The risk of transmission through saliva is small and its exposure to a wound is not considered a risk factor for transmission, unless a positive patient's blood has also been involved. Likewise this should be considered if the victim is HIV positive and bitten by a non-infected source $[4,67]$.

The transmission of blood-borne viruses is dependant on many things including:

- The victim's vaccination status.

- Whether the source or victim is known to have a positive virus status: HIV, Hepatitis B surface antigen (HBsAg) or Hepatitis C positive.

- Whether the source of the injury is available or willing to be tested.

If the source is HIV positive, expert advice should be sought from a suitable source (Infectious Diseases specialist or virologist) about the use of post-exposure prophylaxis (PEP). There is no standard PEP therapy for hepatitis C, however, current advice is for Hepatitis C PCR testing at 4-6 weeks post-exposure and referral to again a suitable specialist if sero-conversion occurs. Hepatitis B transmission is the most common virus transmitted, and is documented as being 100 times more infectious than HIV and present in up to $75 \%$ of Hepatitis B positive patients' saliva. An accelerated course of Hepatitis B vaccine is often given in non-immune victims, with a single dose of hepatitis B immunoglobulin offered on presentation to all human bite related injuries.

Rabies is another virus documented to have been transmitted via bites, and is a mammal specific pathogen. Wild mammals such as fox, badger and bat related injuries should be thought of as suspicious. Due to its rarity, discussion with an Infectious Diseases specialist is mandatory if it is considered especially as the condition is almost invariably fatal [68].

\section{Tetanus Prophylaxis}

Human bites have been shown to transmit Clostridium tetani spores accounting for $4 \%$ of all tetanus infections, and for this reason tetanus immune status must be quantified. Regarding tetanus immunization. Rhee et al. [69] suggested after reviewing the literature that tetanus vaccine should be administered in traumatic wounds in the form of tetanus toxoid if the last booster was given more than 10 years prior or if history is not reliable or available, and as tetanus immunoglobulin in patients with incomplete primary immunization or to patients for whom it has been longer than 10 years since their last booster dose.

\section{Surgical Management}

Most authors advocate initial wash out of wounds in the Accident and Emergency Department for all wounds, before formal debridement takes place in theatres when indicated [31]. Necrotic material is removed together with any foreign particles e.g. chips of teeth that may be found in wounds. Great debate exists whether to repair damaged structures immediately, or after a second look after $48 \mathrm{~h}$ of intravenous antibiosis [70]. Elevation of the injured limb lowers the oedema and limits the associated pain and has been advocated in numerous articles, and found to be of benefit for any type of hand injury [71, 72]. A short period of splintage followed by early active mobilisation with early physiotherapy is of benefit in order to prevent adhesions from forming that would ultimately hinder the return of the injured limb to full range of movement [73, 74]. It is also important that bite injuries are reviewed in a more objective manner using outcome measures [75] and tools including the dynamometer [76] to allow a more accurate idea of their outcome, and help guide future therapies.

\section{CONCLUSION}

Although hand injuries are rarely associated with mortality, they may have significant socio-economic implications on the patient and, more often than not, their entire family [77]. Bite injuries of the hand and their related infections must therefore be monitored vigilantly and managed proactively by experts in this field of surgery. The management of such injuries needs to encompass appropriate antibiosis, a low threshold for surgical intervention, and early mobilisation after a short period of splintage to afford the injured limb the best possible chance to recover fully. 


\section{CONFLICT OF INTEREST}

The authors confirm that this article content has no conflict of interest.

\section{ACKNOWLEDGEMENTS}

Declared none.

\section{REFERENCES}

[1] Kaisha WO, Khainga S. Causes and pattern of unilateral hand injuries. East Afr Med J 2008; 85(3): 123-8.

[2] Sorock GS, Lombardi DA, Hauser RB, Eisen EA, Herrick RF, Mittleman MA. Acute traumatic occupational hand injuries: type, location, and severity. J Occup Environ Med 2002; 44(4): 345-51.

[3] Malik AA, Yousaf N, Khan WS, Ihsan M, Ravenscroft M. Fractures of the wrist and hand. J Perioper Pract 2010; 20(2): 4854

[4] Hand Surgery in the UK Manpower, resources, standards and training. Report of a working party. The British Society for Surgery of the Hand 2007.

[5] Training and resources in hand surgery: profile of hand surgery needs. The British Society for Surgery of the Hand 1992.

[6] Dias, J. Helping the hand. A report on the provision of surgical care for acute hand disorders in the United Kingdom. British Society for Surgery of the Hand 1999.

[7] Medeiros I, Saconato H. Antibiotic prophylaxis for mammalian bites. Cochrane Database Syst Rev 2001; (2): CD001738.

[8] Aigner N, Konig S, Fritz A. Bite wounds and their characteristic position in trauma surgery management. Unfallchirurg 1996; 99(5): 346-50.

[9] Lewis KT, Stiles M. Management of cat and dog bites. Am Fam Physician 1995; 52(2): 479-85, 489-90.

[10] Griego RD, Rosen T, Orengo IF, Wolf JE. Dog, cat, and human bites: a review. J Am Acad Dermatol 1995; 33(6): 1019-29.

[11] Bozkurt M, Kuhlahci Y, Zor F, Kapi E. The management of pit viper envenomation of the hand. Hand 2008; 3(4): 324-31.

[12] Christiano MP, Cardoso DC, Raymundo MS. Contextual analysis and epidemiology of spider bite in Southern Santa Catarina State, Brazil. Trans R Soc Trop Med Hyg 2009; 103(9): 943-8.

[13] Perron AD, Miller MD, Brady WJ. Orthopedic pitfalls in the ED: fight bite. Am J Emerg Med 2002; 20(2): 114-7.

[14] Moran GJ, Talan DA. Hand infections. Emerg Med Clin North Am 1993; 11(3): 601-19.

[15] Wiggins ME, Akelman E, Weiss AP. The management of dog bites and dog bite infections to the hand. Orthopedics 1994; 17(7): 61723

[16] Rothe M, Rudy T, Stanković P. Treatment of bites to the hand and wrist--is the primary antibiotic prophylaxis necessary? Handchir Mikrochir Plast Chir 2002; 34(1): 22-9.

[17] Talan DA, Citron DM, Abrahamian FM, et al. Bacteriologic analysis of infected dog and cat bites. Emergency Medicine Animal Bite Infection Study Group. N Engl J Med 1999; 340: 85-92.

[18] Goldstein EJ, Citron DM, Wield B, et al. Bacteriology of human and animal bite wounds. J Clin Microbiol 1978; 8: 667.

[19] Figueiredo JF, Borges AS, Martínez R, et al. Transmission of hepatitis $\mathrm{C}$ virus but not human immunodeficiency virus type 1 by a human bite. Clin Infect Dis 1994; 19: 546-7.

[20] Bartholomew CF, Jones AM. Human bites: a rare risk factor for HIV transmission. AIDS 2006; 20: 631-2.

[21] Shapiro CN. Transmission of hepatitis viruses. Ann Intern Med 1994; 120(1): 82-4.

[22] http: //www.uptodate.com/contents/soft-tissue-infections-due-tohuman-bites/abstract/7

[23] Vidmar L, Poljak M, Tomazic J, Seme K, Klavs I. Transmission of HIV-1 by human bite. Lancet 1996; 347(9017): 1762

[24] Dusheiko GM, Smith M, Scheuer PJ. Hepatitis C virus transmitted by human bite. Lancet 1990; 336: 503-4.

[25] Davis LG, Weber DJ, Lemon SM. Horizontal transmission of hepatitis B virus. Lancet 1989; 1: 889-93.

[26] Robinson RA, Pugh RN. Dogs, zoonoses and immunosuppression. J R Soc Promot Health 2002; 122(2): 95-8.
Oya J, Hanai K, Miura J, et al. Diabetic gangrene in multiple fingers and toes after a dog bite in an elderly patient with type 2 diabetes. Intern Med 2011; 50(12): 1303-7.

[28] Presutti RJ. Bite wounds. Early treatment and prophylaxis against infectious complications. Postgrad Med 1997; 101(4): 243-4, 246$52,254$.

[29] Zubowicz VN, Gravier M. Management of early human bites of the hand: a prospective randomized study. Plast Reconstr Surg 1991 88(1): 111-4.

[30] Broder J, Jerrard D, Olshaker J, Witting M. Low risk of infection in selected human bites treated without antibiotics. Am J Emerg Med 2004; 22(1): 10-3.

[31] Dire DJ, Hogan DE, Walker JS. Prophylactic oral antibiotics for low-risk dog bite wounds. Pediatr Emerg Care 1992; 8(4): 194-9.

[32] Brakenbury PH, Muwanga C. A comparative double blind study of amoxycillin/clavulanate $v s$ placebo in the prevention of infection after animal bites. Arch Emerg Med 1989; 6: 251.

[33] Rittner DA, Fitzpatrick DK, Corfield DA. Are antibiotics indicated following human bites? Emerg Med J 2005; 22(9): 654

[34] Cummings P. Antibiotics to prevent infection in patients with dog bite wounds: a meta-analysis of randomized trials. Ann Emerg Med 1994; 23(3): 535-40.

[35] Callaham M. Controversies in antibiotic choices for bite wounds Ann Emerg Med 1988; 17: 1321

[36] Dire DJ, Hogan DE, Riggs MW. A prospective evaluation of risk factors for infections from dog-bite wounds. Acad Emerg Med 1994; 1: 258.

[37] Callaham M. Prophylactic antibiotics in common dog bite wounds: a controlled study. Ann Emerg Med 1980; 9: 410-4.

[38] Morgan M, Palmer J. Dog bites. BMJ 2007; 334: 413.

[39] Morgan M. Methicillin-resistant Staphylococcus aureus and animals: Zoonosisor humanosis? J Antimicrob Chemother 2008; 62: 1181-7. South Med J 2003; 96(4): 407-9.

[40] Bradshaw SE. Endocarditis due to Staphylococcus aureus after minor dog bite. Int J Infect Dis 2006; 10(4): 315-9.

[41] Houshian S, Seyedipour S, Wedderkopp N. Epidemiology of bacterial hand infections. Int J Infect Dis 2006; 10(4): 315-9.

[42] Weinzweig N, Gonzalez M. Surgical infections of the hand and upper extremity: a county hospital experience. Ann Plast Surg 2002; 49: 621-7.

[43] Wade T, Booy R, Teare EL, Kroll S. Pasteurella multocida meningitis in infancy - (a lick may be as bad as a bite). Eur J Pediatr 1999; 158(11): 875-8.

[44] Westling K, Farra A, Cars B, et al. Cat bite wound infections: A prospective clinical and microbiological study at three emergency wards in Stockholm, Sweden. J Infect 2006; 53: 403-7.

[45] Schlichthaar H, Rohrer $T$, Schuster G, Lehnert H. Interstitia pneumonia and sepsis due to a Pasteurella multocida infection. Deutsch Med Wochenschr 1995; 120(46): 1582-6.

[46] Mahapatra AN, Mulcahy D. Pasteurella multocida osteomyelitis following a dog bite. Br J Med Sci 2002; 171(1): 56.

[47] Anderson BE, Neuman MA. Bartonella spp. as emerging human pathogens. Clin Microbiol Rev 1997; 10: 203.

[48] Koehler JE, Sanchez MA, Garrido CS, et al. Molecular epidemiology of bartonella infections in patients with bacillary angiomatosis-peliosis. N Engl J Med 1997; 337: 1876-83.

[49] Pers C, Gahrn-Hansen B, Frederiksen W. Capnocytophaga canimorsus septicemia in Denmark, 1982-1995: review of 39 cases. Clin Infect Dis 1996; 23: 71.

[50] Lion C, Escande F, Burdin JC. Capnocytophaga canimorsus infections in human: review of the literature and cases report. Eur Epidemiol 1996; 12: 521.

[51] Stiegler D, Gilbert JD, Warner MS, Byard RW. Fatal dog bite in the absence of significant trauma: Capnocytophaga canimorsus infection and unexpected death. Am J Forensic Med Pathol 2010; 31(2): 198-9.

[52] Baker AS, Rouff KL, Madoff S. Isolation of Mycoplasma species from a patient with seal finger. Clin Infect Dis 1998; 27(5): 116870

[53] Dahl E. Wound infections on board ship--prevention, pathogens, and treatment. Int Marit Health 2011; 62(3): 186-90.

[54] Graves MH, Janda JM. Rat-bite fever (Streptobacillus moniliformis): A potential emerging disease. Int J Infect Dis 2001; 5: $151-5$ 
[55] Lichte P, Kobbe P, Taeger G, Nast-Kolb D, Hiemer R, Oberbeck R. Bite injuries of the hand. Unfallchirurg 2009; 112(8): 719-26; quiz 727.

[56] Eyres KS, Allen TR. Skyline view of the metacarpal head in the assessment of human fight-bite injuries. J Hand Surg Br 1993; 18(1): 43-4.

[57] Tucker SC, Josty I. Compartment syndrome in the hand following an adder bite. J Hand Surg Br 2005; 30(4): 434-5.

[58] Terry P, Mackway-Jones K. Antibiotics in non-venomous snakebite. Emerg Med J 2002; 19(2): 142.

[59] Lee JY, Teoh LC, Leo SP. Stonefish envenomations of the hand--a local marine hazard: a series of 8 cases and review of the literature. Ann Acad Md Singapore 2004; 33(4): 515-20.

[60] Talan DA, Abrahamian FM, Moran GJ, Citron DM, Tan JO, Goldstein EJ. Clinical presentation and bacteriologic analysis of infected human bites in patients presenting to emergency departments. Clin Infect Dis 2003; 37(11): 1481-9.

[61] College of Emergency Physicians: Clinical policy for the initial approach to patients presenting with penetrating extremity trauma. Ann Emerg Med 1999; 33: 612-36.

[62] Management of animal bites. Prodigy guidance. www.prodigy.nhs.uk/qrg/bites animal.pdf

[63] Holm M, Tarnvik A. Hospitalization due to Pasteurella multocidainfected animal bite wounds: correlation with inadequate primary antibiotic medication. Scand J Infect Dis 2000; 32(2): 181-3.

[64] Goldstein E. Bites. In: Mandell, Douglas and Bennett's Principles and practice of infectious diseases. USA: Churchill Livingstone 2005; pp. 3553-6.

[65] Khajotia RR, Lee E. Transmission of human immunodeficiency virus through saliva after a lip bite. Arch Intern Med 1997; 157(16): 1901.

[66] Smoot EC, Choucino CM, Smoot MZ. Assessing risks of human immunodeficiency virus transmission by human bite injuries. Plast Reconstr Surg 2006; 117(7): 2538-9.
[67] Smith DK, Grohskopf LA, Black RJ, et al. Antiretroviral postexposure prophylaxis after sexual, injection-drug use, or other nonoccupational exposure to HIV in the United States: recommendations from the U.S. Department of Health and Human Services. MMWR Recomm Rep 2005; 54: 1-20.

[68] Health Protection Agency Centre for Infection, 61 Colindale Avenue, London NW9 5EQ (www.hpa.org.uk/infections/default. $\mathrm{htm}$ )

[69] Rhee P, Nunley MK, Demetriades D, Velmahos G, Doucet JJ. Tetanus and trauma: a review and recommendations. J Trauma 2005; 58(5): 1082-8

[70] Philipsen TE, Molderez C, Gys T. Cat and dog bites. What to do? Guidelines for the treatment of cat and dog bites in humans. Acta Chir Belg 2006; 106(6): 692-5.

[71] Mitnovetski S, Kimble F. Cat bites of the hand. ANZ J Surg 2004 74(10): 859-62.

[72] Haughton DN, Jordan D, Malahias M, Hindocha S, Khan WS Principles of hand fracture management. Open Orthop J 2012; 6(1): 43-53.

[73] Kall S, Vogt PM. Surgical therapy for hand infections. Part I Chirurg 2005; 76(6): 615-25; quiz 626-7.

[74] Soe NH, Jensen NV, Dahlin L, Johansen HK. Acute infections of the hand. Ugeskr Laeger 2009; 171(14): 1189-93.

[75] Khan WS, Jain R, Dillon B, Clarke L, Fehily M, Ravenscroft M The 'M2 DASH'- Manchester-modified disability of the arm, shoulder and hand Score. Hand 2008; 3(3): 240-4.

[76] Mafi P, Mafi R, Hindocha S, Griffin M, Khan WS. A systematic review of dynamometry and its role in hand trauma assessment. Open Orthop J 2012; 6(1): 95-102.

[77] Malik A, Khan W. Editorial: Recent Advances and Developments in Hand Surgery. Open Orthop J 2012; 6(1): 11-3.

Received: March 1, 2014

(C) Malahias et al.; Licensee Bentham Open.

This is an open access article licensed under the terms of the Creative Commons Attribution Non-Commercial License (http://creativecommons.org/licenses/by-nc/3.0/) which permits unrestricted, non-commercial use, distribution and reproduction in any medium, provided the work is properly cited. 